\title{
Development of PCM Reactor for Methane Steam Reforming
}

\author{
Nobuhiro MARUOKA ${ }^{1)}$ and Tomohiro AKIYAMA ${ }^{21}$ \\ 1) Institute of Multidisciplinary Research for Advanced Materials, Tohoku University, 2-1-1 Katahira, Aoba-ku, Sendai $980-8577$ \\ Japan. E-mail: maruoka@tagen.tohoku.ac.jp 2) Center for Advanced Research of Energy Conversion Materials, \\ Hokkaido University, Kita 13 Nishi 8, Kita-ku, Sapporo 060-8628 Japan. E-mail: takiyama@eng.hokudai.ac.jp
}

(Received on December 4, 2009; accepted on April 30, 2010)

\begin{abstract}
This paper describes the experimental investigation of a new methane steam reformer utilizing waste heat through the latent heat storage material called "phase change material (PCM)". The intermittently released waste heat such as steelmaking off gas was first converted to a continuous, constant temperature heat source in the form of latent heat of the PCM. Then, the stored heat in the PCM was supplied to methane to induce an endothermic steam-reforming reaction. In the experiments, a laboratory scale reformer in which packed beds of nickel porous catalyst was circumferentially covered by PCM of copper was intermittently heated from outside by a burner and the transient local temperatures were monitored. The results revealed that the PCM temperature was constant in spite of intermittent heating and that hydrogen was generated continuously. The proposed system could possibly produce hydrogen with less $\mathrm{CO}_{2}$ emission than that produced by a conventional hydrogen generator. This could allow the integration of two processes in the steelmaking and hydrogen production industries.
\end{abstract}

KEY WORDS: phase change material; latent heat storage; high temperature waste recovery; methane steam reforming; hydrogen production; steelmaking.

\section{Introduction}

Most industrial high temperature processes based on batch operation emit high temperature waste heat intermittently; hence, it is difficult to recover waste heat from such processes. For example, high temperature waste heat is emitted during steel making using the LD converter process. ${ }^{1-4)}$ It should be noted that one charge of 250 tons of hot metal to the LD converter produces as much as $31500 \mathrm{Nm}^{3}$ of LD off gas (LDG) as a byproduct due to oxygen that is blown into the hot metal to achieve decarburization. LDG, whose composition is $65 \% \mathrm{CO}-17 \% \mathrm{CO}_{2}-$ $17 \% \mathrm{~N}_{2}-1 \% \mathrm{H}_{2}$, can usually be effectively used as fuel in steelworks, for example, for heating blasting air in a hot stove furnace or for generating electricity. The temperature of LDG, at the point of generation, becomes very high due to huge exothermic heat produced during the decarburization reaction. However, presently, technical difficulties prevent the recovery of sensible heat from such a high temperature gas. Thus, the development of a new heat recovery method for the hot waste heat is strongly required.

From the viewpoint of exergy theory, ${ }^{3-13)}$ it is necessary to keep the LDG sensible heat at the highest levels possible to enable its effective utilization in other processes. In addition, as the temperature increases, the efficiency of work done using thermal energy increases. Previous reports ${ }^{6-13}$ ) have concluded that high temperature waste heat such as LDG with temperatures over $1300 \mathrm{~K}$ must be supplied to endothermic processes requiring high temperature heat of around $1300 \mathrm{~K}$, such as coal gasification, natural gas re- forming, and limestone decomposition. Such high temperature waste heat should never be used for generating hot water at $353 \mathrm{~K}$ or steam at $473 \mathrm{~K}$ with a high temperature drop, because the thermodynamic theory states that exergy is lost once the temperature drops even if the heat loss is negligible.

For utilizing high temperature waste heat, especially intermittently emitted heat, it is necessary that the waste heat acts as a constant temperature heat source and the method of heat storage is suitable. A new heat storage material with large latent heat called the metallic phase change material $(\mathrm{PCM})^{12-16)}$ has already been proposed for high temperature applications. The PCM stores the sensible heat of waste heat in the form of latent heat due to melting and then releases the thermal energy at a fixed melting point of the PCM during solidification. Generally, the latent heat of the PCM at its melting point is over 100 times larger than the sensible heat. For example, the specific heat of copper is $24.5 \mathrm{~J} \mathrm{~K}^{-1} \mathrm{~mol}^{-1}$ and its latent heat is $13.3 \mathrm{~kJ} \mathrm{~mol}^{-1}$. The PCM system can regenerate thermal energy from high temperature waste heat without a large temperature drop if the PCM is selected such that its melting point is close to the temperature of the waste heat. This leads to efficient energy saving on the basis of the concept of exergy. The encapsulation of a copper ball, plate and mesh with a metallic nickel film by using an electroplating method has been reported. ${ }^{14-16)}$ The results revealed that the electroplating method has a high potential to be used for coating the PCM.

A new concept of heat recovery that involves endother- 
mic chemical reactions and not sensible heat has been proposed. $^{7-13)}$ This concept is based on energy cascade utilization. Endothermic reactions play an important role in almost all industrial processes, and fossil fuel is consumed to supply the reaction heat. Therefore, combining high temperature waste heat and endothermic reactions can save energy. In this study, the methane steam reforming reaction shown in Eq. (1) was selected as the combination reaction for the heat recovery of $\mathrm{LDG}$.

$$
\mathrm{CH}_{4}+\mathrm{H}_{2} \mathrm{O} \rightarrow \mathrm{CO}+3 \mathrm{H}_{2} \quad \Delta H_{298}=206 \mathrm{~kJ} / \mathrm{mol} \ldots
$$

Thus, intermittently emitted high temperature waste heat such as LDG, which is emitted only during the oxygen blowing period, is stored in the PCM and then converted to a constant temperature heat source that is used for the methane steam reforming reaction. The methane steam reforming reaction normally occurs at over $800^{\circ} \mathrm{C}$, and therefore, copper is selected as the PCM in this study. The temperature of the LD converter changes repeatedly, whereas the temperature of the PCM reactor is always constant at the melting point of copper, i.e., at $1356 \mathrm{~K}$. It should be noted that the heat stored by the PCM during the oxygen blowing period is supplied to carry out the endothermic reaction through the PCM during all periods. If the reaction temperature decreases by using the technique of hydrogen separation membrane, which shifts the equilibrium of the steam reforming reaction and reduces the reaction temperature, ${ }^{17-22)}$ it is appropriate to select another material as the PCM which has lower range of melting point.

So far, the preparation of PCMs using spherical ${ }^{14,15)}$ and mesh-shaped $^{16)}$ copper and system analysis ${ }^{9-13)}$ have been conducted for a high temperature system rather at over $1000^{\circ} \mathrm{C}$. These analyses concluded that natural gas consumption, enthalpy flow, $\mathrm{CO}_{2}$ emission, cost, and exergy loss of hydrogen production were only $59.6 \%, 59.7 \%$, $62.8 \%, 86.5 \%$, and $65.8 \%$ of those of the conventional system, respectively. ${ }^{11)}$ However, the experimental study of recovering waste heat for producing hydrogen has been never reported although experimental studies for a low temperature PCM system have often been reported. ${ }^{23-27)}$ Therefore, the aim of this study is to investigate the thermal property of the steam reformer with a copper PCM experimentally. In the experiments, a laboratory scale reformer in which packed beds of nickel porous catalyst was circumferentially covered by PCM of copper was intermittently heated from outside and the transient local temperatures and the gas composition were monitored. The results suggest that a new process for coproducing steel and hydrogen can be realized. In other words, the proposed system will contribute to promoting energy saving by reducing the generation of hydrogen gas in chemical industries.

\section{Experiment}

Figure 1 shows a schematic diagram of the experimental equipment of a new PCM methane steam reformer. It mainly consists of seven parts; furnace with acetylene burner, steam reformer with PCM, steam generator, methane cylinder, flow meter, water trap and gas chromatography. Because it is predicted that the temperature distribution is existed in the PCM reformer due to the en-

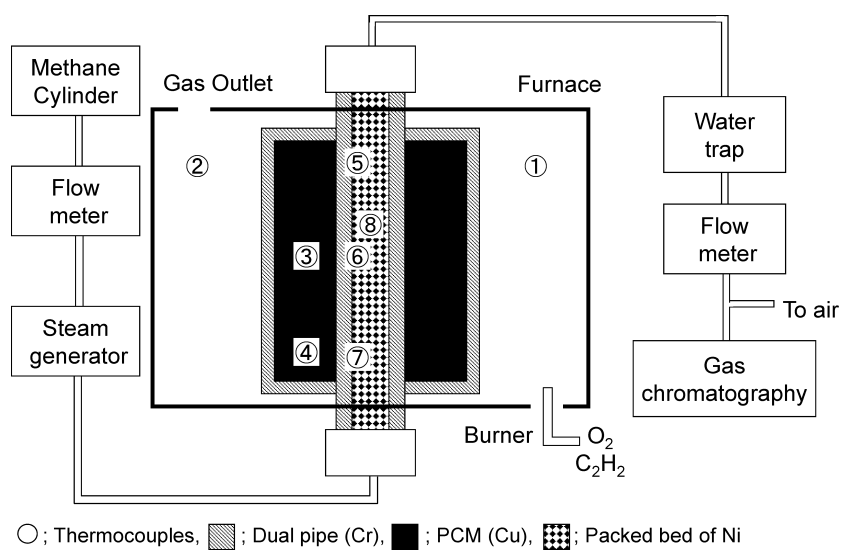

Fig. 1. Schematic diagram of experimental apparatus for developing new methane steam reformer with PCM, in which local temperature was monitored by eight thermocouples and compositions of outlet gas, gas chromatography. (1) Frame, (2) Furnace, (3) Middle of the PCM, (4) Bottom of the PCM, (5) Upper of the reactor surface, (6) Middle of the reactor surface, (7) Bottom of reactor surface, (8) Reaction gas.

dothermic reaction of methane steam reforming, the local temperature was measured at eight points by using a $\mathrm{Pt}-\mathrm{Pt} / \mathrm{Rh} 13 \%$ thermocouple during the experiment. The number (1)-8 indicate the temperature measurement locations. Figure 2 shows the structure and dimension of the reactor, which consists of a machined copper as PCM, dual pipe and the both covers made of chromium. The combination of cupper and chromium was selected from the results of previous study. ${ }^{16}$ ) From the four viewpoints of melting point; $1083^{\circ} \mathrm{C}(1356 \mathrm{~K})$, heat storage density of large latent heat per cubic meter; $209 \mathrm{~kJ} / \mathrm{kg}$, reasonable price, and high thermal conductivity, copper was employed as a material of PCM. Latent heat of copper was used for storing heat over $1000^{\circ} \mathrm{C}(1273 \mathrm{~K})$ in temperature. Porous nickel (marketed as Celmet), having $500 \mathrm{~m}^{2} / \mathrm{m}^{3}$ in specific surface area and $99.9 \%$ in purity, was embedded as catalyst of reforming media in inner tube of dual pipe.

In the experiments, mixed gas of methane and steam as raw materials was first introduced into the reformer after being filled with nitrogen as inert gas from the bottom of inner tube. Next, both furnace and reformer were heated up over melting temperature of PCM by using an acetylene burner. The burner was on and off to simulate waste heat emission in the industrial batch process of high temperature such as a steelmaking converter. This procedure was repeated several times by changing interval time. The local temperature was measured by a thermocouple at eight points as shown in Fig. 1 and gas composition at the outlet was analyzed continuously by gas chromatography during the experiment.

\section{Results and Discussions}

Figure 3 shows the temperature and gas composition changes of the experimental equipment which was heated by acetylene burner intermittently. In the experiment, the flowrate of methane based gas was $0.17 \mathrm{NL} / \mathrm{s}$. Temperature changes at eight points, as shown in Fig. 1, were monitored. Roughly speaking, the temperatures of the PCM (No. 3, 4), 


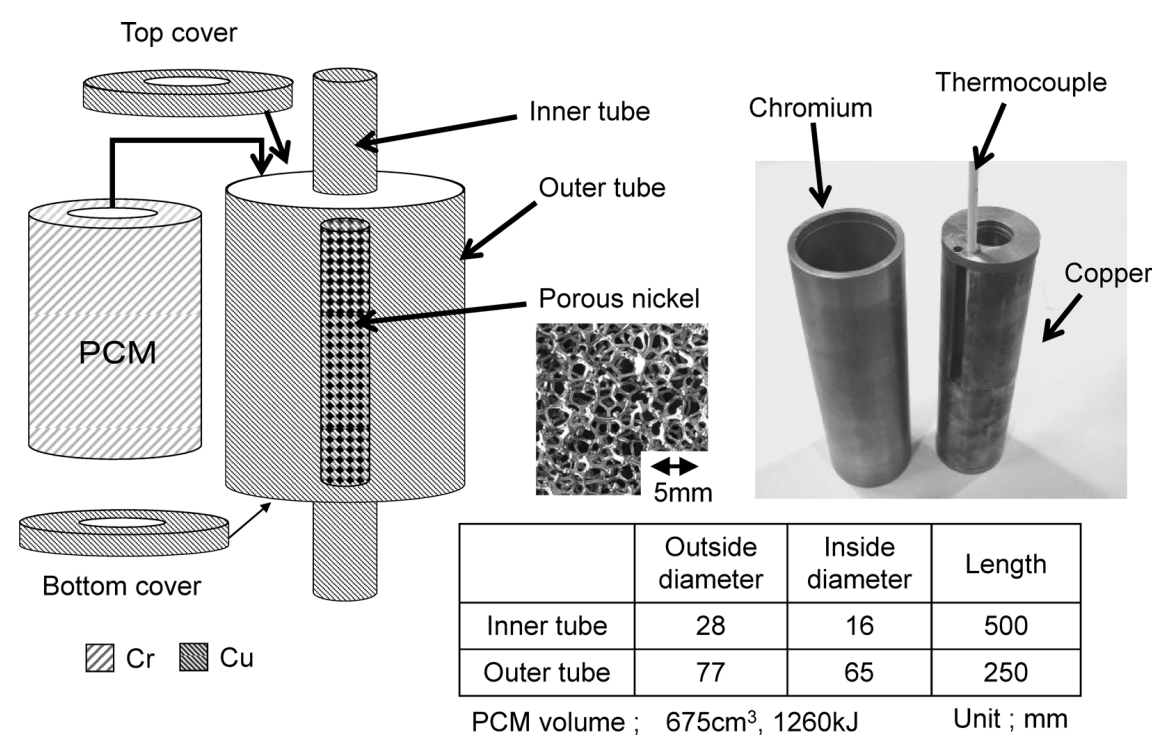

Fig. 2. Structure of the reactor with PCM, in which cupper cylinder was embedded in chromium pipe. Porous nickel is introduced into the inner tube of the reactor, which is marketed as Celmet.

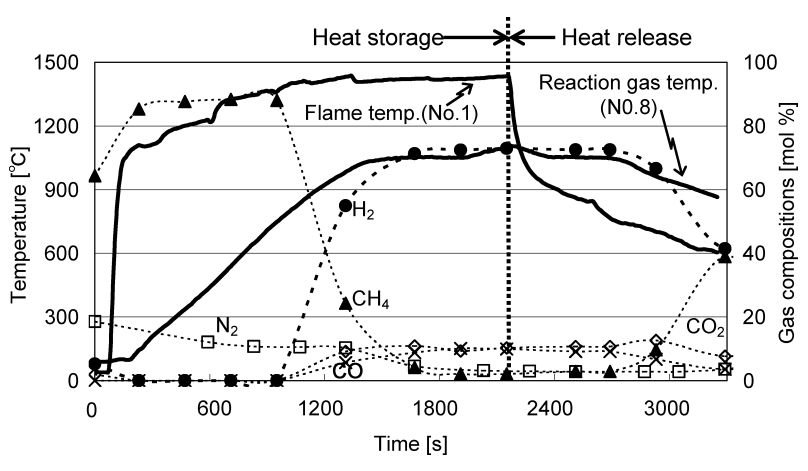

Fig. 3. Changes in temperature and gas composition during the heating and cooling period under the gas flowrate of $0.03 \mathrm{~L} / \mathrm{s}$, in which number of temperatures is location of thermocouples shown in Fig. 1.

reactor surface (No. 5-7), and reaction gas (No. 8) indicated the same trend because of the high thermal conductivity of copper. They rose simultaneously together with increasing temperature of the furnace (No. 1) during the heating period. In contrast, the gas temperature in the inner tube reached $1000^{\circ} \mathrm{C}(1273 \mathrm{~K})$ and kept stable at $1083^{\circ} \mathrm{C}$ $(1356 \mathrm{~K})$ of the cupper melting point. The results showed that combustion heat from the burner was stored by melting the PCM in the form of latent heat of copper, as expected. Shortly after the gas temperature reached over $1083^{\circ} \mathrm{C}$ $(1356 \mathrm{~K})$, the acetylene burner was turned off. After that, the reactor started to be cooled down naturally. During the cooling period of the reactor, temperatures of the PCM and the product gas were kept as constant value of $1083^{\circ} \mathrm{C}$ $(1356 \mathrm{~K})$ over $600 \mathrm{~s}$ and then were decreased gradually, demonstrating the effect of PCM. The heat stored in the PCM is supplied to reaction heat during the cooling period instead of burner heating. When the temperature of PCM became less than the melting point of copper, the burner was again turned on for heating the reactor up. This procedure was several times repeated to simulate the industrial gas discharged from the batch process.

In the typical steam reformer of natural gas, a mixture of methane and steam was reformed to hydrogen and carbon monoxide by the help of $\mathrm{Ni}$ based catalyst under the condition of $800^{\circ} \mathrm{C}(1073 \mathrm{~K})$ approximately. In the experiment, the analysis of the outlet gas according to the gas chromatography showed that both hydrogen and carbon monoxide were generated when the PCM temperature was over $1000^{\circ} \mathrm{C}$. This result means, the steam reforming reaction occurred after the burner was being turning off. While keeping constant temperature as $1083^{\circ} \mathrm{C}$, the reactant gas; $90 \% \mathrm{CH}_{4}-10 \% \mathrm{~N}_{2}$, was changed into the reformed gas; $3 \% \mathrm{CH}_{4}-74 \% \mathrm{H}_{2}-10 \% \mathrm{CO}-10 \% \mathrm{CO}_{2}-3 \% \mathrm{~N}_{2}$. This indicates that the foamed nickel in the inner tube behaved as a good catalyst for methane steam reforming reaction at the melting point of PCM, although the compositions of catalyst is not well-designed for reforming because the gas composition measured by gas chromatography was quite similar to the equilibrium compositions of $0 \% \mathrm{CH}_{4}-74 \% \mathrm{H}_{2}-21 \% \mathrm{CO}-$ $2.8 \% \mathrm{CO}_{2}-2.6 \% \mathrm{~N}_{2}$ at the that temperature.

In the practical use of PCM in the industrial process, it must always keep constant temperature even when the waste heat is not emitted due to batch operation. The PCM stores the waste heat, which is emitted intermittently, and then releases continuously as a heat source. To validate the performance required of the PCM under the batch-wise thermal conditions, the equipment was heated up until the PCM temperature exceeded the melting point of PCM and then stopped. When the PCM temperature dropped to less than the melting point of PCM, the equipment is heated up again. This procedure was several times repeated. Figure 4 shows changes in the temperature and gas composition during a cyclic heating, in which the acetylene burner was turned on and off at several times. The results showed that the temperature of PCM and the compositions of product gas were not changed and then hydrogen generated constantly even during intermittent heating. The gas compositions at outlet were almost equal to ones in Fig. 3. The both results demonstrate that the waste heat can be utilized for generating hydrogen by using latent heat storage. The results also suggest a possibility of the recovery equipment of waste heat from a batch process in the high temperature industries, in which the PCM can store the waste heat and 


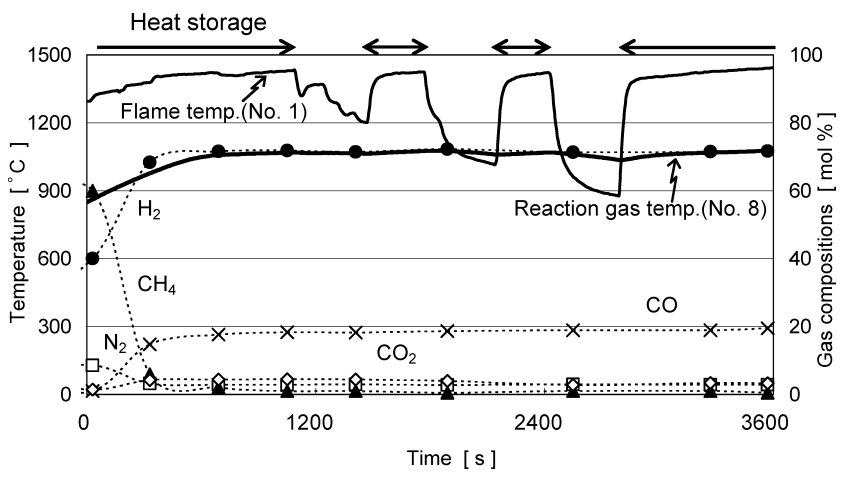

Fig. 4. Changes in temperature and gas composition during the repeated heating test under gas flow rate of $0.08 \mathrm{~L} / \mathrm{s}$, in which number of temperatures is location of thermocouples shown in Fig. 1.

then convert discontinuous waste heat into continuous heat source at constant temperature.

The different flowrates of methane was determined to be $0.02,0.03,0.08,0.17$ and $0.25 \mathrm{NL} / \mathrm{s}(1,2,5,10$ and $15 \mathrm{NL} /$ $\mathrm{min}$ ) for investigating the effect of gas flowrate on efficiency of heat recovery. Figure 5 shows the gas compositions of outlet gas at various gas flowrates. Note that most methane was converted when the methane flowrate was less than $0.17 \mathrm{NL} / \mathrm{s}$. However, the conversion ratio of methane drops drastically over the flowrate of $0.17 \mathrm{NL} / \mathrm{s}$. This means that efficiency of heat recovery reached a maximum value at the flowrate less than $0.17 \mathrm{NL} / \mathrm{s}$ under the experimental conditions of this study. In contrast, the temperature of outlet gas from the reactor was almost constant.

The changes in the thermal and chemical enthalpies of the gas were calculated from the volume, composition, and temperature of the inlet and outlet gases, using the modified enthalpy method. ${ }^{10,11)}$ Modified enthalpy is consisted of two parts; chemical enthalpy and thermal enthalpy. Chemical enthalpy indicates own energy of material at standard conditions and thermal one, the state of material as a function of temperature. Thus, when the temperature of material becomes higher the thermal enthalpy increases but the chemical enthalpy does not change. Figure 6 shows the effect of the gas flowrate on the thermal and chemical enthalpies per unit time. Thermal enthalpy increases with the gas flowrate. Chemical enthalpy also increases with the gas flowrate, but becomes constant above the gas flowrate of $0.17 \mathrm{NL} / \mathrm{s}$. Gains in chemical enthalpy are always larger than in thermal enthalpy, except for the case of $0.25 \mathrm{NL} / \mathrm{s}$ in flowrate. This was caused by the fact that steam reforming reaction is not completed at the flowrate of $0.25 \mathrm{NL} / \mathrm{s}$. This fact can be understood clearly from Fig. 7. Figure 7 shows the effect of the gas flowrate on the thermal and chemical enthalpies per unit volume of gas. The changes in the recovered thermal enthalpy per unit volume of gas with respect to the gas flowrate are insignificant, because the temperature of the outlet gas is almost the same at various flowrates. In contrast, the recovered chemical enthalpy decreases above the gas flowrate of $0.17 \mathrm{NL} / \mathrm{s}$. This indicates that the reaction of methane steam reforming is incomplete above the gas flowrate of $0.17 \mathrm{NL} / \mathrm{s}$. From the viewpoint of thermochemical storage, heat should be recovered by chemical enthalpy, not thermal one, because thermal enthalpy cannot be stored

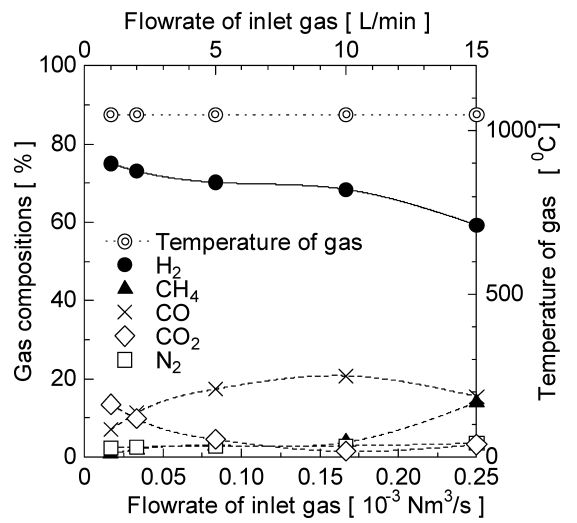

Fig. 5. Effect of the inlet gas flow rate on the gas compositions.

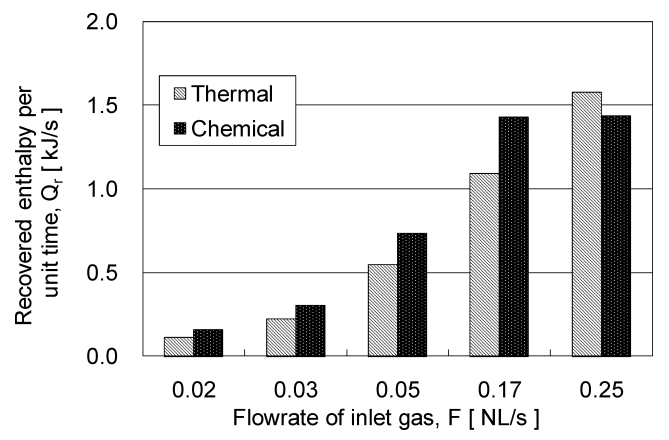

Fig. 6. Effect of the gas flow rate on the thermal and chemical enthalpies per unit time recovered by reforming methane.

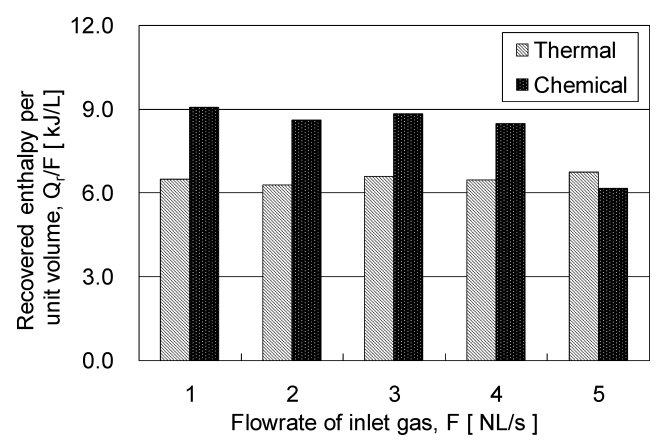

Fig. 7. Effect of the gas flow rate on the thermal and chemical enthalpies per unit volume recovered by reforming methane.

for a long time. Thus, the condition of $0.17 \mathrm{NL} / \mathrm{s}$ in flowrate was most appropriate for thermochemical storage under the experimental conditions of this study. Furthermore, excellent catalyst might improve the efficiency of enthalpy recovery, because reaction rate is significantly contributed to the efficiency of enthalpy recovery.

Figure 8 shows the process system diagram of the proposed methane steam reformer. Here, the circle represents a process and the solid arrows into and out from the circle are the substance before and after the change, respectively. A white arrow represents an intermediary energy, which is acceptance or release energy of the process, such as electricity, heat of endothermic reaction and exothermic reaction. The proposed system with PCM consists of the following five processes; furnace, heat exchanger with PCM, reactor, heat sink and latent heat storage. During the period of heat storage, fuel and air come into the furnace and supply heat 


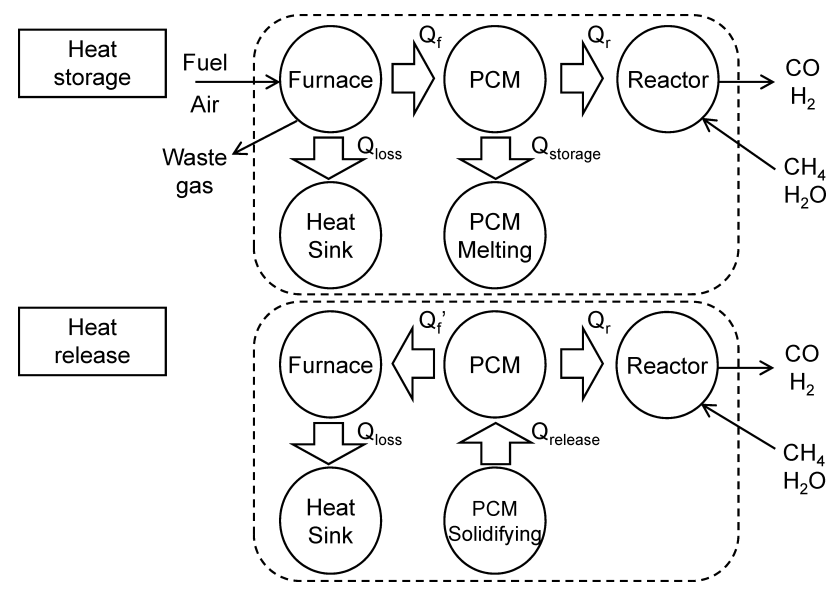

Fig. 8. Process-system diagram of the proposed reformer of methane-steam with PCM.

to the PCM heat exchanger. A part of heat is consumed for reforming methane and the rest of heat is stored in the form of latent heat as defined in Eq. (2).

$$
Q_{\mathrm{f}}=Q_{\mathrm{r}}+Q_{\text {storage }}
$$

During the period of heat release, fuel is not supplied because of batch operation. Reaction heat for reforming methane is supplied by the heat stored in the form of the latent heat by melting of PCM. The heat stored in the PCM is also consumed as heat loss from the surface of the PCM heat exchanger to the furnace as defined in Eq. (3).

$$
Q_{\text {release }}=Q_{\mathrm{f}}^{\prime}+Q_{\mathrm{r}}
$$

Latent heat of PCM for storing waste heat is defined below,

$$
\begin{aligned}
\Delta H_{\mathrm{L}} & =Q_{\text {storage }} \times t_{\text {storage }} \\
& =Q_{\text {release }} \times t_{\text {release }}
\end{aligned}
$$

Therefore, operating time for heat storage and release can express as follows,

$$
\begin{aligned}
& t_{\mathrm{s}}=\frac{\Delta H_{\mathrm{L}}}{Q_{\text {storage }}}=\frac{\Delta H_{\mathrm{L}}}{Q_{\mathrm{f}}-Q_{\mathrm{r}}} \\
& t_{\mathrm{r}}=\frac{\Delta H_{\mathrm{L}}}{Q_{\text {release }}}=\frac{\Delta H_{\mathrm{L}}}{Q_{\mathrm{f}}^{\prime}-Q_{\mathrm{r}}}
\end{aligned}
$$

Table 1 shows the operating time and enthalpy changes in heat storage and release, which were calculated from the equations abovementioned. With increasing gas flowrate, the time for heat storage increased and the time for heat release decreased. The time for heat storage was defined as the time required for melting PCM. If the gas flowrate is large, the heat required for the reaction is large. Then, the time for heat storage becomes long. In the case of heat release, the heat stored in the PCM supplies reaction heat and so the time for heat release decreased with increasing gas flowrate.

Figure 9 shows the content of the heat stored in the PCM. A part of the heat stored was used for reaction and the other was released as heat loss. The result shows that the heat stored in the PCM can be used more efficiently with increasing flowrate. This is because a part of heat
Table 1. Operating time and enthalpy changes in heat storage and release.

Heat Storage Period
\begin{tabular}{|c|c|c|c|c|}
\hline $\mathrm{F}$ & $\mathrm{t}_{\text {storage }}$ & $\mathrm{Q}_{\text {storage }}$ & $\mathrm{Q}_{\mathrm{r}}$ & $\mathrm{Q}_{\mathrm{f}}$ \\
\hline $\mathrm{L} / \mathrm{s}$ & $\mathrm{s}$ & $\mathrm{kJ} / \mathrm{s}$ & $\mathrm{kJ} / \mathrm{s}$ & $\mathrm{kJ} / \mathrm{s}$ \\
\hline 0.03 & 402 & 3.1 & 0.53 & 3.7 \\
\hline 0.08 & 480 & 2.6 & 1.29 & 3.9 \\
\hline 0.17 & 522 & 2.4 & 2.52 & 4.9 \\
\hline
\end{tabular}

Heat Release Period
\begin{tabular}{|c|c|c|c|c|}
\hline $\mathrm{F}$ & $\mathrm{t}_{\text {release }}$ & $\mathrm{Q}_{\text {release }}$ & $\mathrm{Q}_{\mathrm{r}}$ & $\mathrm{Q}_{\mathrm{f}}^{\prime}$ \\
\hline $\mathrm{L} / \mathrm{s}$ & $\mathrm{s}$ & $\mathrm{kJ} / \mathrm{s}$ & $\mathrm{kJ} / \mathrm{s}$ & $\mathrm{kJ} / \mathrm{s}$ \\
\hline 0.03 & 402 & 3.1 & 0.53 & 2.6 \\
\hline 0.08 & 390 & 3.2 & 1.29 & 1.9 \\
\hline 0.17 & 354 & 3.6 & 2.52 & 1.0 \\
\hline
\end{tabular}

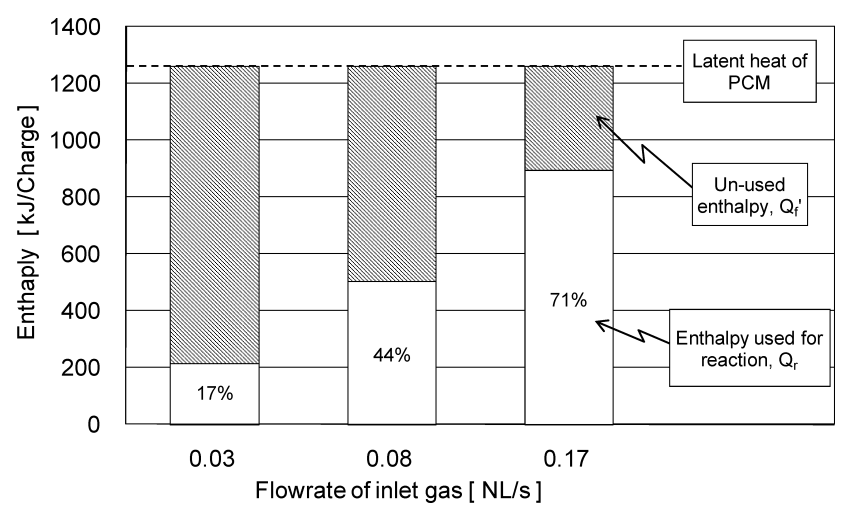

Fig. 9. Effect of the inlet gas flowrate on the enthalpy availability in the PCM.

stored in the PCM is lost in the form of radiation to the furnace. The results, given in Fig. 6 and 8, revealed that the optimum flowrate of the inlet gas was $0.17 \mathrm{~L} / \mathrm{s}$ for efficient heat recovery in the experimental apparatus of this study.

\section{Conclusion}

A new steam reformer which utilizes intermittently released waste heat through the PCM was experimentally examined. The following conclusions were obtained:

(1) The developed reformer with PCM can changed waste heat released from batch process intermittently to continuous heat source at constant temperature.

(2) The developed reformer generated hydrogen continuously during the period of burner off.

(3) Porous material of pure nickel, marketed as Celmet, was enough for producing hydrogen at the melting point of copper as PCM.

(4) The equations of system design for optimizing the proposed methane steam reformer by utilizing PCM and waste heat were derived. The flowrate of inlet gas was most significant main factor for efficient heat recovery. If the flowrate is too much, made the reaction of methane steam reforming occurs incompletely. If the flowrate is too small, the stored heat consumes much as heat loss. The steam reformer proposed had an optimum value in gas flowrate; a value of $0.17 \mathrm{NL} / \mathrm{s}$ in gas flowrate was best in this study.

\section{Acknowledgment}

The authors would like to thank ITEC CO., LTD. for ex- 
perimental advice and development of equipment.

\section{Nomenclature}

$Q_{\mathrm{f}}$ : Heat supplied from the furnace to the PCM $(\mathrm{kJ} / \mathrm{s})$

$Q_{\mathrm{f}}{ }^{\prime}$ : Heat released from the PCM to the furnace $(\mathrm{kJ} / \mathrm{s})$

$Q_{\text {loss }}$ : Heat loss in the furnace $(\mathrm{kJ} / \mathrm{s})$

$Q_{\mathrm{r}}$ : Reaction heat of methane steam reforming $(\mathrm{kJ} / \mathrm{s})$

$Q_{\text {release }}$ : Heat released from the PCM to the reactor $(\mathrm{kJ} / \mathrm{s})$

$Q_{\text {storage }}$ : Heat stored in the form of latent heat by melting the PCM $(\mathrm{kJ} / \mathrm{s})$

$t_{\text {storage }}$ : The time for storing waste heat (s)

$t_{\text {release }}$ : The time for releasing waste heat (s)

$\Delta H_{\mathrm{L}}:$ Latent heat of PCM $(\mathrm{kJ})$

\section{REFERENCES}

1) H. W. Gudenau, W. Dahl, M. Koerfer and M. Scheiwe: Steel Res., 61 (1990), No. 4, 157.

2) H. W. Gudenau, W. Dahl, M. Koerfer and M. Scheiwe: Steel Res., 61 (1990), No. 4, 164.

3) Y. Shimazaki, A. Akisawa and T. Kashiwagi: Proc. of the Int. Conf. on Thermodynamic Analysis and Improvement of Energy Systems, TAIES'97, Chinese Society of Engineering Thermophysics and American Society of Mechanical Engineers, Beijing, (1997), 313.

4) N. Hayajawam, Y. Wakazono, T. Kato, Y. Suzuoki and Y. Kaya: IEEE Trans. Energy Convers., 14 (1999), No. 3, 795.

5) O. F. Dilmaç and S. K. Özkan, Int. J. Exergy, 5 (2008), No. 2, 241.

6) T. Mizuochi, T. Akiyama, T. Simada, E. Kasai and J. Yagi: ISIJ Int., 41 (2001), No. 2, 1423.

7) T. Akiyama, H. Sato, A. Muramatsu and J. Yagi: ISIJ Int., 33 (1993), No. 11, 1136.

8) T. Akiyama, K. Oikawa, T. Shimada, E. Kasai and J. Yagi: ISIJ Int., 40 (2000), No. 3, 286.

9) N. Maruoka, T. Mizuochi, H. Purwanto and T. Akiyama: ISIJ Int., 44
(2004), No. 2, 257

10) H. Purwanto, N. Maruoka and T. Akiyama: J. Chem. Eng. Jpn., 39 (2006), No. 5, 531

11) N. Maruoka, H. Purwanto and T. Akiyama: ISIJ Int., submitted.

12) N. Maruoka and T. Akiyama: ISIJ Int., 42 (2002), No. 11, 1189.

13) N. Maruoka and T. Akiyama: Energy, 31 (2006), No. 10-11, 1632.

14) N. Maruoka, K. Sato, J. Yagi and T. Akiyama: ISIJ Int., 42 (2002), No. 2, 215.

15) N. Maruoka and T. Akiyama: J. Chem. Eng. Jpn., 36 (2003), No. 7, 794.

16) N. Maruoka, M. Asao, T. Miyako, M. Nakamoto and T. Akiyama: JCEJ, 28 (2002), 713.

17) P. Bernardo, G. Barbieri and E. Drioli: Chem. Eng. Sci., 65 (2010), No. 3, 1159.

18) S. A. Simakov and M. Sheintuch: AIChE Annual Meeting, Conf. Proc., American Institute of Chemical Engineers, New York, (2005), 10123.

19) S. A. Simakov and M. Sheintuch: AIChE J., 54 (2008), No. 10, 2735.

20) J.-H. Kim, B.-S. Choi and J. Yi: J. Chem. Eng. Jpn., 32 (1999), No. 6,760 .

21) S. Wieland, T. Melin and A. Lamm: Chem. Eng. Sci., 58 (2002), No. $12,2551$.

22) Xu, Jianguo, Froment and F. Gilbert:, AIChE J., 35 (1989), No. 1, 88.

23) M. A. Hamdan and I. Al-Hinti: Appl. Therm. Eng., 24 (2004), 1935.

24) A. Kaizawa, N. Maruoka, A. Kawai, H. Kamano, T. Jozuka, T. Senda and T. Akiyama: Heat Mass Transfer/Waerme- und Stoffuebertragung, 44 (2008), No. 7, 763.

25) A. Kaizawa, H. Kamano, A. Kawai, T. Jozuka, T. Senda, N. Maruoka and T. Akiyama: Energy Convers. Manag., 49 (2008), No. 4, 698.

26) A. Kaizawa, H. Kamano, A. Kawai, T. Jozuka, T. Senda, N. Maruoka, N. Okinaka and T. Akiyama: ISIJ Int., 48 (2008), No. 4, 540 .

27) A. Venkata Ramayya and K. N. Ramesh: Int. J. Energy Res., 22 (1998), 411. 